\title{
EDITING THE ORDINARY: EXCEPTIONAL RENDITION OF NGO-KA-KI HOUSE
}

\author{
MOHD FAIRUS KHOLID, PUTERI MAYANG BAHJAH ZAHARIN \& KARTINI KASMURI \\ Centre of Studies for Architecture, Faculty of Architecture, Planning and Surveying, \\ Universiti Teknologi MARA, Malaysia
}

\begin{abstract}
The Chinese embodiment in most major cities in South-East Asia is widely being articulated through the existence of shop house. Its renowned status has overshadowed the "Attap" house that was built during the early Chinese migration. In Malaysia, evidence has shown that shop house was first derived as a simple "Attap" hut that was built by the Chinese merchant to service the tin miners. The "Attap" house is also said to lay the basis for shop house. This paper aims to explore the Chinese spatial and spiritual essence through the interpretation of the layering of the Chinese "Attap House". Certain perspective of Chinese family structure and their perception on cosmological epitome, profitability and growth, and the concept of flexibility through the creation of 'Kaki Lima' are thoroughly identified. "Kaki Lima", or five-foot way in English, is translated as "Ngo-Ka-Ki" in Chinese dialect. As such, the interpretations of the Chinese "Attap House" are edited and formulated into a scheme, which is not merely a house but rather incorporated as a manifesto. The "Ngo-Ka-Ki House" is a setting to investigate the paradox of Chinese essence that alters the spatial quality of a living quarter, thus anchoring the idea of Chinese living in a broader spectrum.

Keywords: chinese embodiment, shop house, five-foot way, spatial quality, living quarter.
\end{abstract}

\section{INTRODUCTION}

The Chinese form the world's largest ethnic group with over 1.3 billion people [1]. In Malaysia, the Chinese is the second highest Overseas Chinese community in the world [2] and is the second biggest ethnic group after the Malays. Known as "orang cina" in Malay, most of the Chinese in Malaysia are of Han Chinese ancestry who, majority of them migrated to this country in the early 19th century to operate new tin mines. Their population are primarily urban with dominance in the business and commerce sector.

The Chinese in Malaysia are considered as one of the wealthiest ethnic groups with most of their income generated through market and trading activities. They are also a keen property investor, with strong desire in residential properties. One family is said to own multiple apartments [3]. In terms of architecture, the Chinese bring a form of art into their buildings that distinctively mark their strong Chinese essence.

Chinese in general, often maintain a close-knit family structure. Although the Chinese household is said to be large with extended families living under one roof, this conception however, was challenged by Fei [3]. According to Fei, on average, a Chinese family in the past did not have a dozen or five generations living together but rather more to 4 to 6 people per household. In the Malaysian context today, due to the process of urbanization, this household has somewhat become a nuclear, which is small in size, diverse in structure and possess strong individual interests.

The Chinese is relatively rich in its culture, tradition and superstition. Despite the modernized world of capitalist enterprise and technology, the cosmology of Chinese religion continues to thrive [4], which often creates tensions between logic and superstition. Houses are organized according to the principles of "Feng Shui" and business deals are carried out in correlation with the Zodiac calendar. 


\section{THE CHINESE DWELLING}

The Chinese representations are concealed within the artefacts of their early arrival in South-East Asia. Some may translate the artefacts into an intangible embodiment that upholds the essence of the early Chinese. These artefacts are inculcated into their customs and traditions through art, culture, food, belief, lifestyle and architecture. In South East Asia, traded commodities were actively taken place in the 9th to 10th century in main entrepot cities such as Srivijaya, Champa, Palembang, Malacca, and Borneo. This period also marked the peak of the China maritime trade which led to the assimilation of Chinese artefacts. Following this, the advent of Chinese Diaspora during the colonial period in the 19th century, had witnessed a large number of migrations into South-East Asia, leading to the dissemination of Chinese artefacts in most of the South-East Asian cities.

\subsection{The Chinese living quarters in the early days}

Despite the assumption, whether implicitly or explicitly that the colonial town is wholly created by the colonizers, the early development of this town is said to be highly influenced by the Chinese. This is due to the fact that the Chinese are more urban-adapted and business minded people and needed a space where trading activities could take place [5]. As such, the concept of home working through living quarter cum working space, which is later known as the "Shop House" was established in this part of town (Fig. 1). This concept is believed to be the first of its kind and can be widely seen in most of the South East Asian cities today. The shop house consists of two floors, with living quarter or private residential on the first and working space or public family business on the ground (Fig. 2). This sort of arrangement allows direct contact between demand and supply, customers and traders and indirectly helps to generate the household income. In Java, the shop house acts as a stepping-stone for investment, where it is being applied by most families as a tool to accumulate sufficient capital to build a decent home [6].

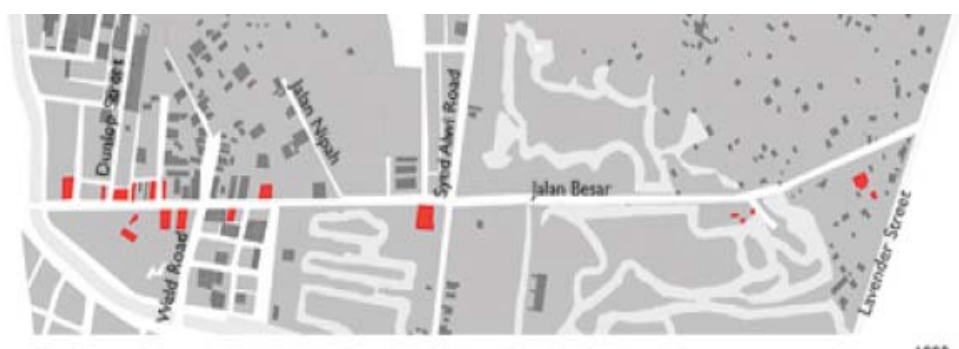

$1893-1909$

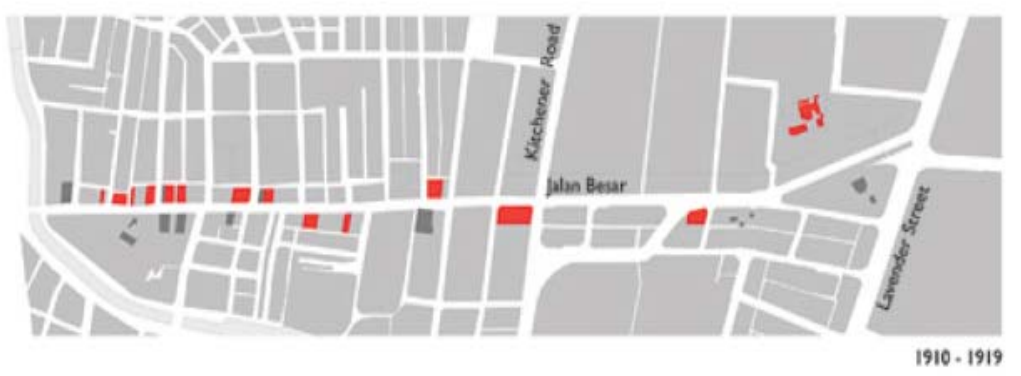

Figure 1: The growth of shop houses in Penang in the 19th century. (Source: https://www.ura.gov.sg/skyline/skyline11/skyline11-04/article-05.html.) 


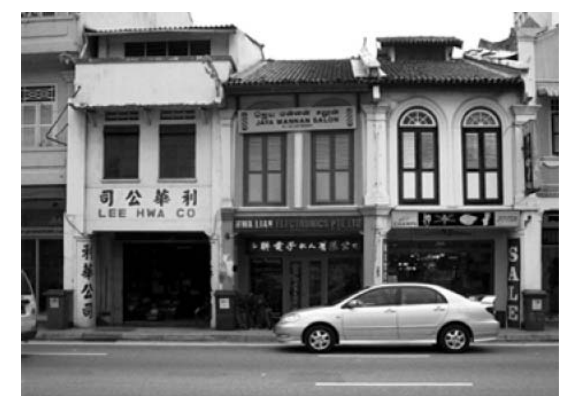

Figure 2: The shop houses in Penang in 1888. (Source: https://www.ura.gov.sg/skyline/ skyline11/skyline11-04/article-05.html.)

\subsection{The "Clan"}

Wealth is the main priority for the Chinese. In seeking prosperity, the early Chinese settlers formed an association called "Clan" which is a benevolent organization among the overseas Chinese communities who shared a common background or ancestral village. This association supports its members in overcoming economic difficulty, social ostracism, and oppression and provides facilities such as shop house, temple and dormitory which formed an ethnical enclave that strongly holds the Chinese essence [7]. The "Clan" enclave has a high value for the colonizers. Despite expressing authentic identity, the colonizers have taken advantage of this enclave to captivate a propaganda which aims at civilizing the locals [6]. By turning the enclave into a China Town, the colonizers are able to strengthen their power and yet, respecting the cultures and alluring prosperity among the locals. As of today, China Town has become a major economical enclave that generates profit for its city.

\subsection{The "Attap" house}

The shop house does not only represent the Chinese dominance but is an amalgamation of multiple influences that combines the western terrace house character and the southern China flavours. The essence of the shop house lies in its concept of home working, but the edifice is layered by the colonial envelope represented through the influence of Neoclassical, Art Deco, Victorian and International Style. Its oriental identity can be seen through its ornaments and the presence of the courtyard cum air well (Fig. 3).

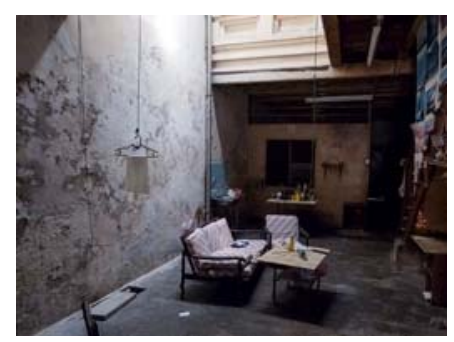

Figure 3: The courtyard in a shop house. (Source: https://ahtongtailor.files.wordpress.com/ 2012/08/r00106171.jpg.) 
Apart from the renowned shop houses, the Chinese are also often associated with the "Attap" house [8]. The "Attap" house is a typical farmhouse, which can be found in the remote areas of Indo-China, Borneo, Malaysia and Singapore. The dwelling has a unique structure and is made of indigenous materials with wide overhang "Attap" roof and walls. "Attap" in general is a thatch made from palm fronds and symbolises the typical attributes of a Malay traditional house. The difference with the Malay house is that an "Attap" house stood directly on the ground as opposed to stilts which is similar to the Chinese hut built in China. The "Attap" house is divided into three segments; the centre and both ends. The owner of the house will occupy the centre portion of the house while both ends are being rented out, either to a member of the family or other relatives [8]. The house can be suggested as socially less open, as openings are built only at the front and rear facades. Space arrangement of the middle house is based on three sides of walls; where the ancestral hall is being surrounded by the kitchen or the bedrooms (Figs 4-5).

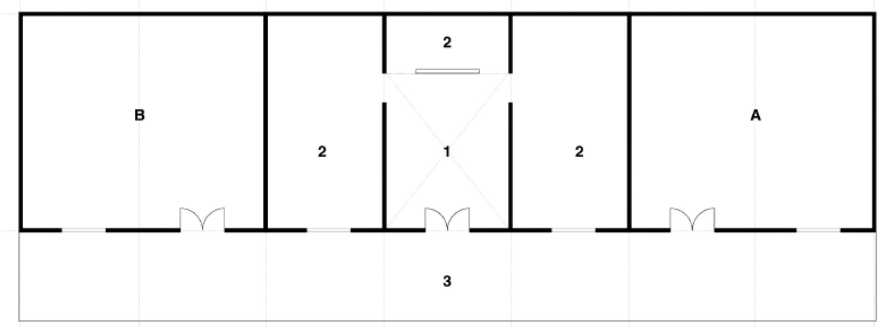

1: Ancestral Hall

2: Room

3: Veranda

A: Expanded Room

B: Expanded Room

Figure 4: The "Attap" house in Singapore.
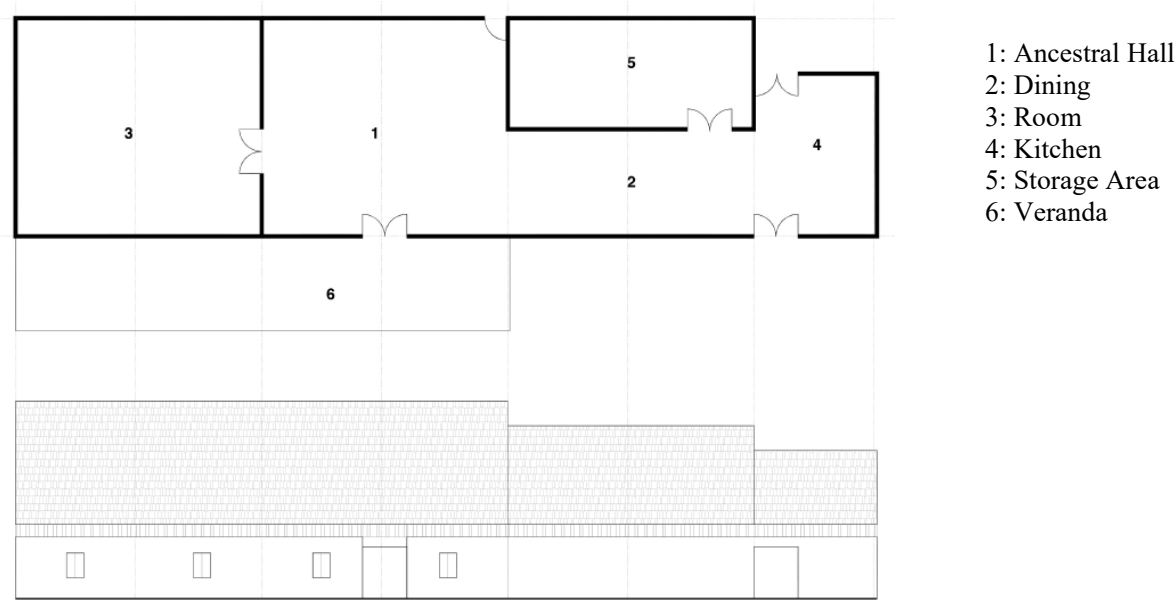

Figure 5: The "Attap" house in Sarawak Cultural Village, Malaysia. 


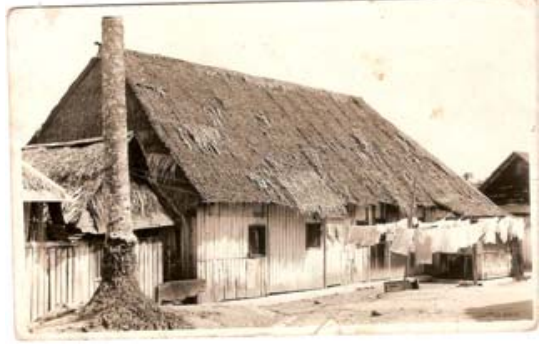

The "Attap" House in the early days

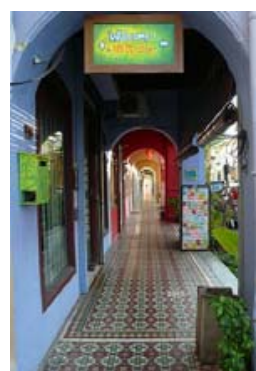

The "Five-Foot Way" of a shop house

Figure 6: The "Attap" house in translation. (Source: Left: http://ching-teoh.com/wp/wpcontent/uploads/2009/04/P1070457.jpg; Right: http://3.bp.blogspot.com/.)

A typical "Attap" house can be extended into a maximum of two rooms wide. This allows the house to be elongated, providing a wide frontage that normally faces the main road and the pedestrian path. A veranda is built to connect the entire frontage of the house and provides a social space for the owner and the rented families. This space is believed to influence the origins of 'five-foot' way in a shop house (Fig. 6).

\subsection{The different representations of Chinese living}

Family size and wealth are the important elements injected in the spatial arrangement of Chinese living. The space is organized in hierarchal manner, as the elders take their position in the centre, with the ancestral hall as the locus point of the main house. The "Attap" house for instance, allows both ends of the unit to be rented out, either for investment or family expansion. It also transcends the notion of flexibility as it resembles modular space that can be altered within the external frame of the house to fit the owner's purpose. For some, these spaces are used to store machinery goods.

In closer look, the layout of the "Attap" house resembles the idea of the Three Bay house in China (Fig. 7). This type of house is often referred to as the basic unit of Chinese homes. Depending on the size and wealth of the family, the Three Bay house can be added on to, often in standard ways. One common extension of the Three Bay house is the creation of a courtyard dwelling which can be shared by the whole family. In Beijing, this concept has been translated into a courtyard house which is made of multiple blocks of the Three Bay house.

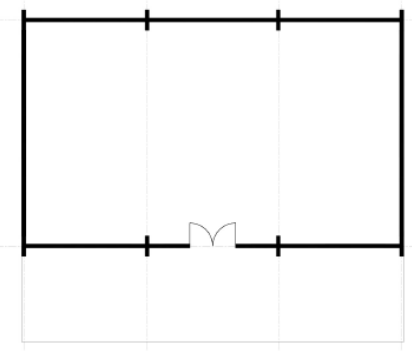

Figure 7: The Three Bay house in China. 
According to Chinese context, three is an exemplar of Chinese preference in odd number. Based on the geomancy approach, symmetrical and balance are best achieved through an odd sequential rhythm. As such, Chinese dwellings can grow into five, seven or nine bays according to its preferences.

Kohl [9], argues that the architecture of the Chinese specifically in Singapore and Malaysia has not been altering its form since the Tang dynasty, as it satisfied with their fitness of purpose, serviceability and aesthetic. Thus, this argument has laid a strong basis to the well-known shop house as an adaptation of the "Attap" house.

\section{THE "NGO-KA-KI" HOUSE}

"Ngo-Ka-Ki" or 'Five-Foot Way' in English and 'Kaki Lima' in Malay, is a Chinese term that refers to a corridor or veranda measured in literally 'five steps' or 'five feet' in length. This term signifies certain typology of space, rather than spatial dimension [10]. The five feet as mentioned in some old Chinese and Japanese literatures, signifies a 'Byabu' which is a painted folding screen and 'Madokoro' which can be classified as the head of a ship [10]. This idea strongly defines the element of a certain typology of space through the presence of an envelope.

Rendering "Ngo-Ka-Ki" as a house creates a parameter into the study of this typology of space. A house is a basic space for living. It represents the closest connection between a man and a space. A house illustrates a manifestation of everyday life occurrences that might take place in between a "Ngo-Ka-Ki"; a tale between semi-public and semi-private, domestic and public realms, traditional and modernity, master and slave, and femininity and masculinity [11].

\subsection{Defining the "Ngo-Ka-Ki"}

Based on the essence of the Chinese "Attap" House, the "Ngo-Ka-Ki" House acts as a counterproposal to many housing projects, particularly high-rise residential in Malaysia. High-rise housing is the epitome of urban life. In many developing countries, the aim towards urbanizing the locals has become its main agenda. It is expected that in 2050, Malaysia will be transformed into a high-income nation. As such, living in urbanized area is inevitable. Living vertically is the future.

The "Ngo-Ka-Ki" House is explicated as the "other house". This house is culturally influenced and provides an alternative to the generic layout (Fig. 8) of many current highrise residential in Malaysia. It intends to translate and reinterpret the Chinese spatial essence into modern application by criticizing the ordinary living represented through the common high-rise residential layout. By transposing the spatial quality, the "Ngo-Ka-Ki House" aims to manifest a new dwelling or housing typology based on Chinese values and perceptions, within the living context of Malaysia.

\subsection{The "Ngo-Ka-Ki" concept}

The epitome of 'Kaki Lima' or 'Five-Foot Way' exists both in traditional Chinese "Attap" house and shop house schemes. This space acts as a catalyst that alters the program of a domestic sphere which can be seen in an "Attap" house, into a public-private sphere such as the shop house. In view of this, the invasion into an ordinary living is initiated through the advent of the presumably habitable space, which is the "Kaki Lima". This concept is dubbed as "Ngo-Ka-Ki", from this point onwards. 


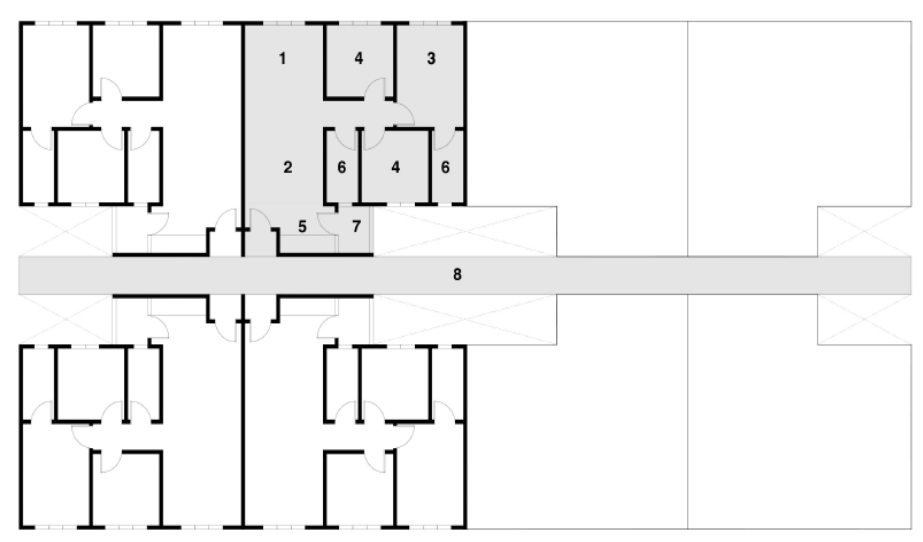

1: Living

2: Dining

3: Master Bedroom

4: Bedroom

5: Kitchen

6: Bathroom/Toilet

7: Utility

8: Double loading corridor

Figure 8: Ordinary apartment arrangement with double loading corridor in Malaysia.

In the modern context of a high-rise residential, the double loading corridor is thoroughly seen and given essence to Ngo-Ka-Ki (Fig. 9). As it is often defined, the function of this corridor has deprived its potentiality as it focuses only as a circulation medium. The idea of 'certain space' has been buried deep within its singular purpose. By challenging this paradox, its purpose is diversified to optimize its functionality. The significance of this diversification is clearly defined if the residential units acknowledge the multiplication. Approaching this, three elements are analyzed as strategies; threshold, flexible layout and service core.

\subsubsection{Threshold}

The introduction of Ngo-Ka-Ki as habitable space has transformed the orientation of a single unit house. As the elongated side is in parallel with the Ngo-Ka-Ki, this allows the threshold to have wider opening, giving more permissible light into the inner space (Figs 910). In conventional design, the opening is usually limited to a single door's width. However, by injecting the Ngo-Ka-Ki, it defeats the corridor as a hostile space through blank wall on both sides.

\subsubsection{Flexible layout}

The Ngo-Ka-Ki House layout is constructed of 5 divisions of basic habitable spaces; living, kitchen and dining, master bedroom and two bedrooms. Each space is separated by a flexible wall, which can be removed and added depending on the owner's needs and preferences. As such, in certain configurations, all spaces can be rented out in smaller units as each unit has individual access due to the elongated frontage along the Ngo-Ka-Ki. This layout contradicts the conventional method, which is fixed and less flexible. The frontage of the unit faces inwards to minimize security and surveillance issues (Fig. 11).

\subsubsection{Service core}

The success of the Ngo-Ka-Ki House scheme depends on the arrangement of the service core. To ensure that the frontage has a full-frontal opening, the service core is placed at the rear of the unit, in parallel with the Ngo-Ka-Ki. Consequently, the core is also divided into five segments serving each habitable space; figuratively expressing the relation between master and slave. The service core, which accommodates storage and toilets, is constructed 
as an independent solid container cube and is attached to the main structure. This configuration makes it conveniently modifiable to fit occupants' requirements (Fig. 10).

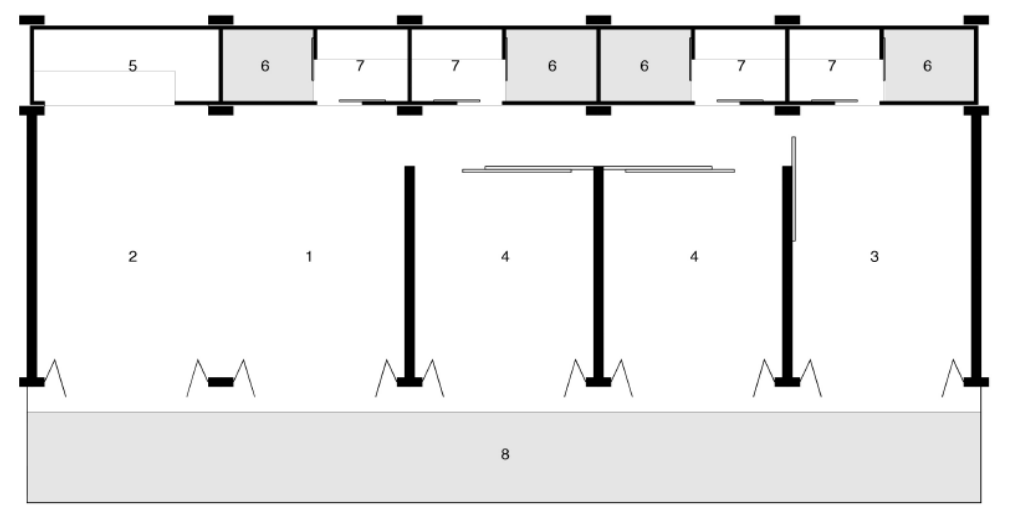

1:Living

2:Dining

3:Master Bedroom

4:Bedroom

5:Kitchen

6:Bathroom/ Toilet

7: Wardrobe/ Storage

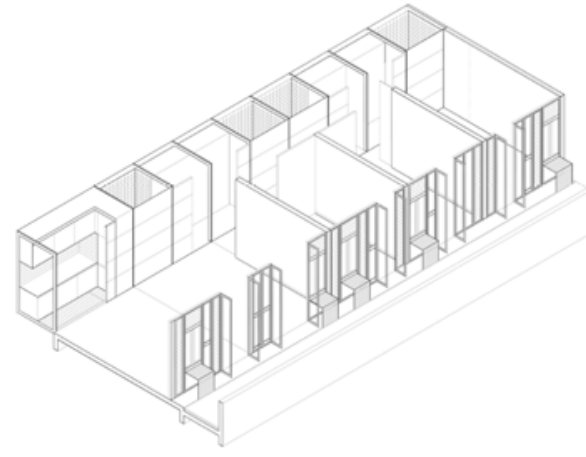

3 bedrooms apartment

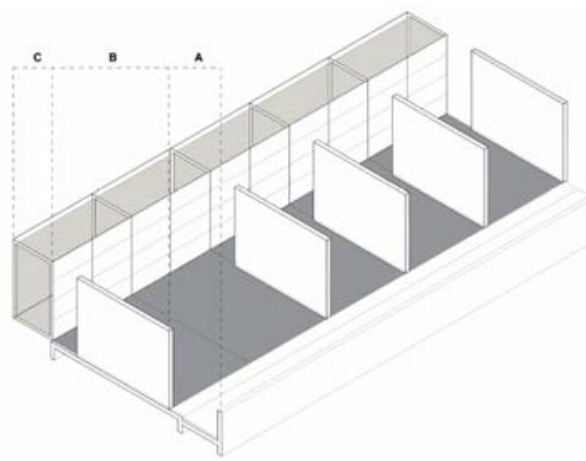

A: Kaki Lima, B: Main House, C: Service Core

Figure 9: The Ngo-Ka-Ki concept.

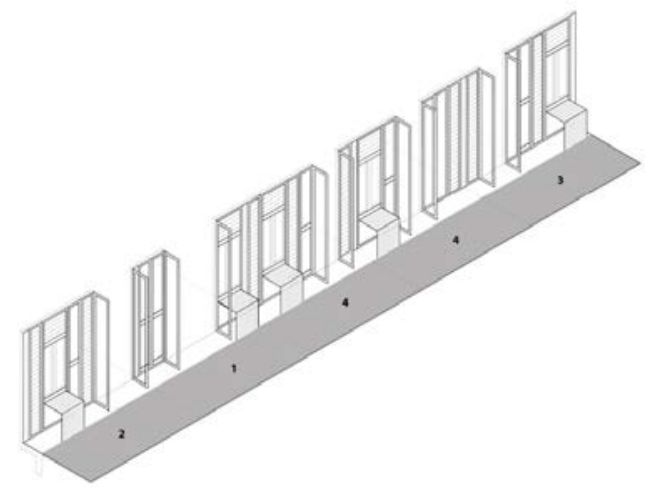

Threshold

1: Living, 2:Dining / SOHO, 3: Master Bedroom, 4: Bedroom / Studio / SOHO

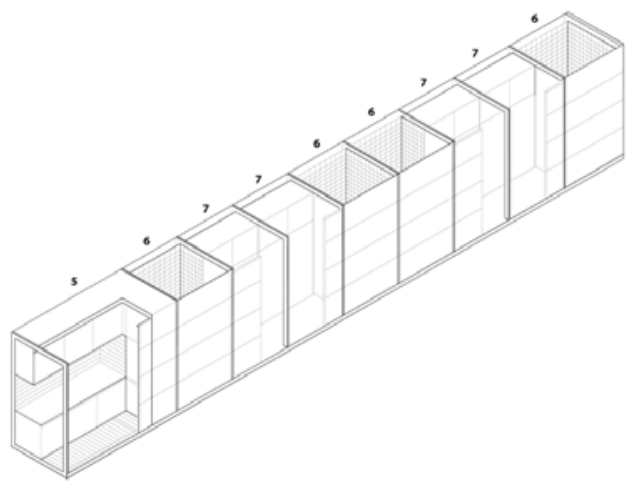

Service core

5: Kitchen, 6: Bathroom/Toilet, 7: Wardrobe/ Storage

Figure 10: Threshold at front unit and service core at rear unit. Both are in parallel. 

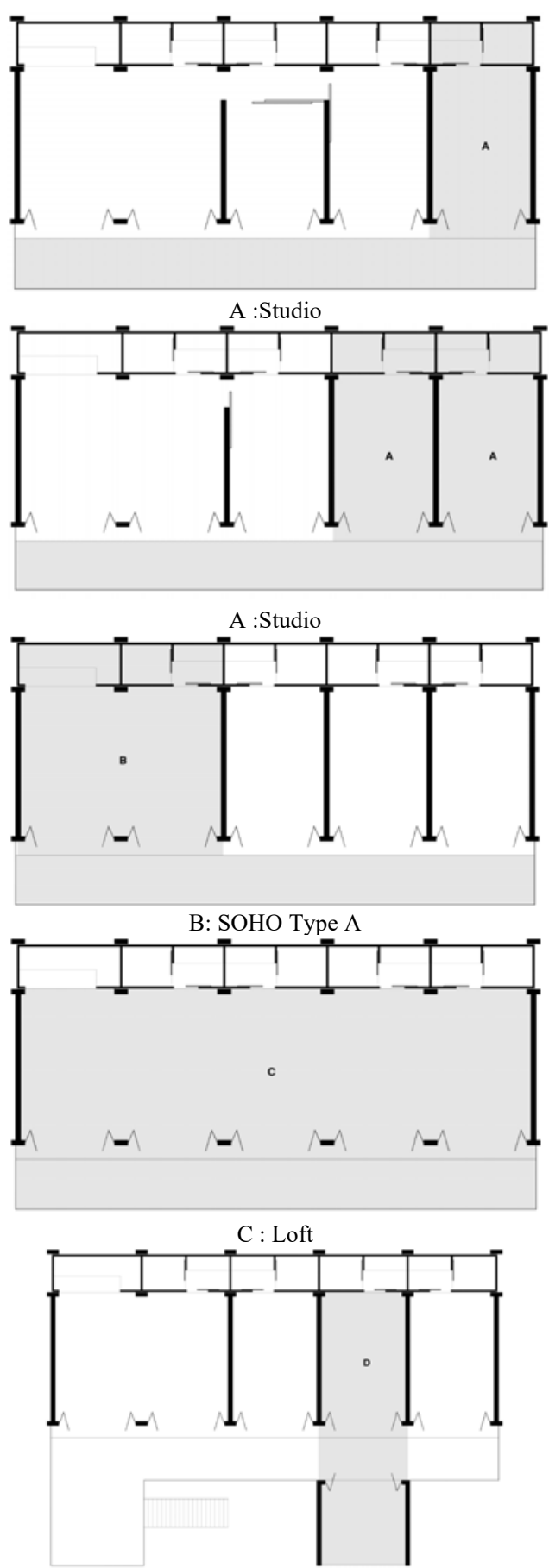

D: SOHO Type B

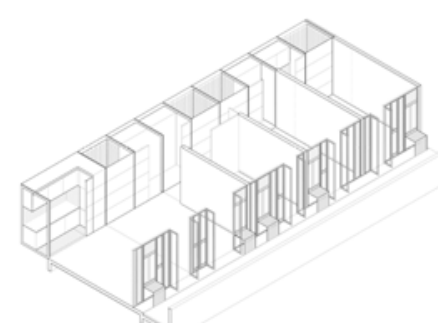

2 Bedroom Apartment with a single studio

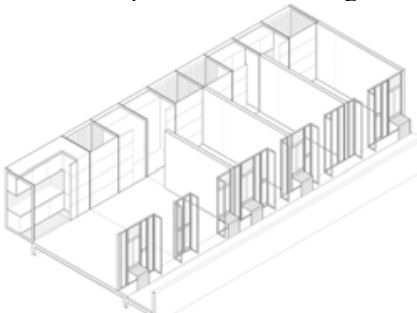

1 Bedroom Apartment with 2 studio apartments

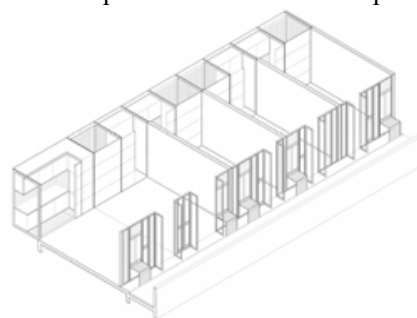

SOHO type A with 3 studio apartments

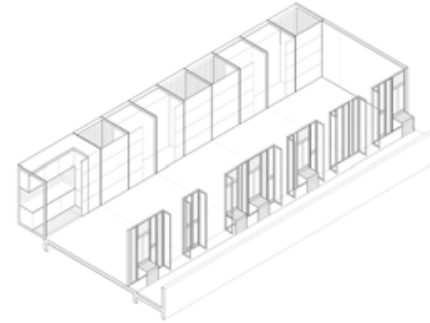

C : Loft

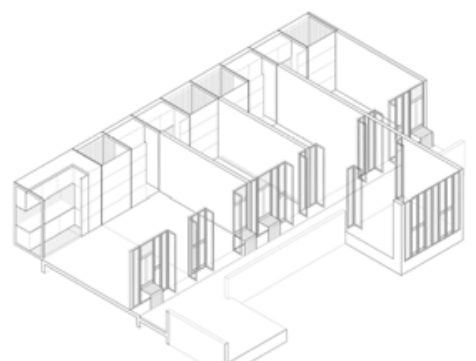

SOHO type A \& type B with 2 studio apartments

Figure 11: Various configurations of internal spaces are made possible with moveable walls and partitions. 


\section{THE RATIONALE BEHIND THE "NGO-KA-KI" HOUSE}

The strategies are devised to address several issues in relation to Chinese values and perceptions in the context of living. These include geomancy and cosmological aspect, profitability and investment and flexibility and growth.

\subsection{Geomancy and cosmological aspect}

The proposed scheme challenges the optimization of space by omitting irregular shapes. It stresses on the idealistic rectangle form to balance the flow of Qi or the cosmic breath as suggested in Feng Shui [12]. Due to rigidity in layout, the interiors of a high rise residential are made flexible to maximize the values of geomancy. As such, the occupants must be able to relate the context of living with their belief and perception, which in this case, responds to the conflicts between facts and fictions.

The thresholds are made wider to ease the flow of Qi into internal spaces [12]. However, the width can be manipulated depending on the needs of its occupants. In the old days, the Chinese design their threshold with various forms of opening, ornaments and materials. By injecting the same ideas, the occupants will be able to enliven the Ngo-Ka-Ki.

The schematic configuration is in tripartite which includes the Ngo-Ka-Ki, the main house and the service core. The services are hidden in a huge container designated at the rear end. The placement of services in this container symbolizes a solid background of a mountain.

The layout of a unit is segregated in a sequence of oddities for a reason; to achieve the optimum symmetrical and hierarchical potentials. However, since the layout is flexible, the facade must be designed in such a way to suit the flexibility of its inner purpose.

\subsection{Profitability and investment}

The division between spaces permits indefinite expansion; spatially and economically. Each segment of the house is able to accumulate profit by the acts of rental, either among the family members or to outsiders, thus resulting in investment linkages within the personal sphere of influence [13]. The spaces can be converted into multiple units, a singlefamily house with two or three bedrooms, a studio apartment, a SOHO, or a loft. This sort of flexibility gives various kinds of profits through different modes of operation.

Integrating business and living under one roof is one of the important essences among the Chinese. Space becomes catalyst to stimuli business. This integration helps to visualize the concept of 'Zero Work' [14], where people are no longer dependable on a specific workplace but rather technological advancement to earn a living.

\subsection{Flexibility and growth}

Flexibility is distinctively embedded in within the Chinese design philosophy. A flexible space is determined through a designated purpose or participation by choice [15]. For instance, most traditional Chinese furniture are designed with flexible attributes that provides the end users the freedom to construct the means of its utilization.

The Ngo-Ka-Ki concept is generated based on this idea. The layout can be arranged in accordance to the preferences of its occupants. Movable panels and thresholds permit family expansion, which give meaning to personalization. 

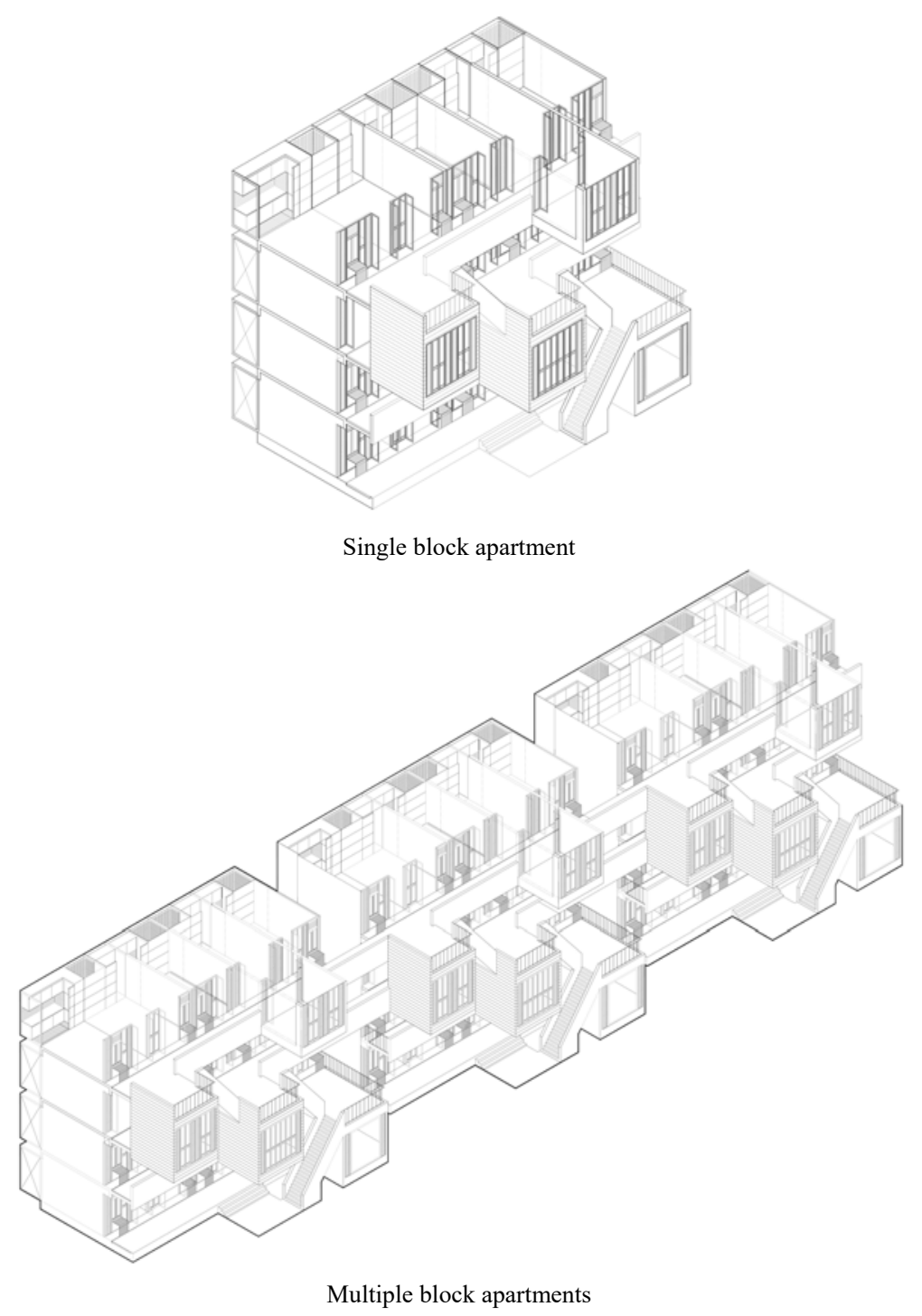

Figure 12: Multiplication of units in various configurations.

\section{CONCLUSION}

The Ngo-Ka-Ki House explores the potentials of a culturally significant utilitarian space as a habitable space. It provides an alternative typology within the boundaries of Chinese culture living. In a broader viewpoint, this concept influences the property market landscape as individual property owners have more flexible options in diversifying the value of their assets. It is safe to presume that this new typology would also result in a new building image for high-rise residential. The reorientation of internal spaces such as the elongated facade that is expandable and enclosed service core at rear of units provide a new dimension and articulation to its facade treatment and site planning. Predominantly in the 
case of high-rise residential, where aesthetics are a sellable factor, it is presumably said that the Ngo-Ka-Ki House concept could be well adopted into different dwelling typologies.

\section{REFERENCES}

[1] Central Intelligence Agency (US), https://www.cia.gov/library/publications/the world-factbook/geos/ch.html-. Accessed on: 5 Aug. 2017.

[2] Wang, P., 6 Places with Strong Chinese Communities Outside Mainland China, http://www.chinawhisper.com/6-places-with-strong-chinese-communities-outsidemainland-china/. Accessed on: 7 Aug. 2017.

[3] Xu, A. \& Xia, Y., The changes in Mainland Chinese families during the social transition: A critical analysis. Journal of Comparative Family Studies, pp. 31-53, 2014.

[4] Malaysian Chinese Ethnography, https:/culturnicity.files.wordpress.com/2011/04/ malaysian-chinese-ethnography.pdf. Accessed on: 5 Aug. 2017.

[5] Loo, Y.M., Architecture and Urban Form: Race and Chinese Spaces in Postcolonial City, Routledge, New York, 2016.

[6] Kusno, A., Shop houses, Chinese Indonesians and other stories, Herb Feith Foundation Seminar Series, Monash University Couldfield Campus, 2016.

[7] Chen, V.F., The Encyclopedia of Malaysia, Volume 5: Architecture, Archipelago Press, Singapore, 1998.

[8] Chan, K.B. \& Tong, C.K., Past Times: A Social History of Singapore, Times Edition, Singapore, 2003.

[9] House Architecture: China, https://depts.washington.edu. Accessed on: 12 Mar. 2017.

[10] Izumida, H., The 1st International Conference of Malay Architecture at Jakarta: Volume 1, www.researchgate.net. Accessed on: 8 Jul. 2017.

[11] Giles, J., The Parlour and The Suburb: Domestic Identities Class, Femininity and Modernity, Berg, New York, 2004.

[12] Lip, E., Feng Shui for the Home, Times Books International, Singapore, 1985.

[13] Piket, K., Personal Sphere of Influence, salesgrowthhub.com. Accessed on: 8 Jun. 2017.

[14] Krumuiede, K., We Are Approaching the End of Work: How Will This Change Our Housing, www.archdaily.com. Accessed on: 3 May 2017.

[15] Schneider, T. \& Till, J., Flexible Housing, Architectural Press, Oxford, 2007. 